\title{
A mathematical model of the double-pipe system with TBCs application
}

\author{
Mariusz Granda ${ }^{1 *}$, Marcin Trojan ${ }^{1}$ \\ ${ }^{1}$ Department of Thermal Processes, Air Protection, and Waste Utilisation Cracow University of Technology, Cracow, Poland
}

\begin{abstract}
Following Rankine's cycle efficiency, steam with ever-higher parameters is used to improve the efficiency of advanced ultra-supercritical power plants. The high steam parameters require the use of expensive high-alloy steels. Therefore, design concepts with reduced investment costs are more and more popular. In the power industry, the use of thermal barrier coatings to protect components exposed to high temperatures is becoming ever more common. The innovative concept is a double-pipe system with a thermal barrier that provides insulation for the primary pipe, in which ultra-supercritical steam flows. On the outside, the pipe is cooled by lower performance steam. The following paper presents a two-dimensional mathematical model of the proposed solution. A set of heat transfer equations allows the determination of the temperature field in the steady and transient-state operation of such a system. The numerical model is compared with the CFD one. The temperature gradient in the inner pipe wall with and without coating was determined. In addition, the response of the wall temperature to the step-change of the steam temperature was investigated. The paper shows that the use of TBCs allows reducing high-alloy steels and improving the handling properties of thick-walled components.
\end{abstract}

\section{Introduction}

The basic cycle that describes the maximum theoretical efficiency of the conversion thermal energy to the mechanical one is the Carnot cycle. Its efficiency depends on the upper temperature of the heat source and the temperature of the lower heat source, where heat is transferred as in Eq. (1):

$$
\eta=1-\frac{T_{L}}{T_{H}}
$$

In classical power plants, where the working fluid is steam, the conversion of thermal to mechanical energy is described by the Rankine cycle. This cycle is practically the same as that proposed by Carnot, due to technical difficulties, the compression of a medium, which is a mixture of both liquid and vapour, to a state in which it is a saturated liquid, is impossible. Hence, the compression in the liquid state is considered [1,2]. Another difference is the heat transfer from the upper (or to the lower) heat source at a constant pressure. Other thermodynamic processes are not affected. According to Eq. (1), the efficiency of the cycle can be improved by rising the upper heat source temperature $\mathrm{T}_{\mathrm{H}}$ or lowering the lower heat source temperature $\mathrm{T}_{\mathrm{L}}$. In the Rankine cycle, the lowering of the temperature $\mathrm{T}_{\mathrm{L}}$, which is also a temperature of the condensation, is achieved by expanding the working fluid to a pressure below atmospheric. Nevertheless, such a solution is constrained by the ambient temperature [2]. The increase in temperature of the upper heat source is a better solution, however, as the temperature rises, the steam pressure must also be increased and additional reheating must be applied. This procedure, also named carnotisation of the cycle, not only increases its efficiency but also avoids the steam condensation on the last stages of the turbine and delivery of the superheated steam to the condenser as well. For temperatures above $540{ }^{\circ} \mathrm{C}$, each $4.7 \%$ increase in steam temperature yields a $1.4 \%$ increase in efficiency, while the same increase in pressure gives only a $0.3 \%$ improvement [2]. Increasing steam parameters, higher Rankine cycle efficiencies have enabled power plants to be distinguished into the following categories:

- subcritical units with steam parameters: 16-17 $\mathrm{MPa}, 540^{\circ} \mathrm{C}$ and $38 \%$ efficiency;

- supercritical units with steam parameters: 22-24 $\mathrm{MPa}, 600-615^{\circ} \mathrm{C}$ and $45 \%$ efficiency;

- ultra-supercritical units with steam parameters $26 \mathrm{MPa}, 620^{\circ} \mathrm{C}, 42-46 \%$ efficiency;

- advanced ultra-supercritical units: $35 \mathrm{MPa}, 700-$ $760^{\circ} \mathrm{C}$, with an efficiency above $50 \%$.

Higher operating parameters have pushed materials engineering to create materials that have higher creep strength and oxidation resistance. Numerous research projects have led to the development of new materials for the energy industry. Thus, four main groups of materials can be distinguished, i.e. low-alloy steels, high-alloy martensitic steels, chromium-nickel steels with austenitic structure and nickel superalloys. Low alloy steels are

*Corresponding author: mariusz.granda@pk.edu.pl 
mainly used for the construction of sub-critical boilers. The operation of components exposed to higher temperatures and pressures will require martensitic steels. In the case of supercritical and ultra-supercritical boilers, a relatively large part of the pressure components is based on high-alloy steels. It is also needed to use nickel superalloys, which considerably raises the total cost of the investment. Table 1 shows the share of materials in boiler components for given operating parameters. Further raising the steam parameters to ultra-supercritical yields a sharp increase in the share of expensive alloys. It should be noted that not the operating parameters but the change in boiler design has a significant impact on the above proportions. In conventional power plants with subcritical parameters, the share of the surface area for water heating, steam evaporation and steam superheating are almost identical $[3,4]$. On the enthalpy-entropy diagram, it can be shown that an increase of the boiler operating parameters decreases the share of surfaces responsible for water heating and evaporation. In ultra-supercritical boilers, the water preheater and evaporator surfaces are so small that the remaining area is designed for steam superheating. The share of high-alloy steels increases, and because of the shifting of these surfaces towards the flame and lack of its water cooling, it is necessary to use nickel superalloys. Cost and material constraints are forcing the industry to look for new solutions that minimise the use of expensive superalloys.

Table 1. The share of materials in boiler components for given operating parameters.

\begin{tabular}{cccc}
\hline & \multicolumn{3}{c}{ Operating parameters } \\
& $18 \mathrm{MPa}$ & $28.5 \mathrm{MPa}$ & $30.3 \mathrm{MPa}$ \\
& $540^{\circ} \mathrm{C}$ & $600^{\circ} \mathrm{C}$ & $650^{\circ} \mathrm{C}$ \\
Material group & The proportion of boiler pressure \\
equipment \\
\hline Low-alloy steels & $80 \%$ & $52 \%$ & $35 \%$ \\
Martensitic steels & $20 \%$ & $31 \%$ & $45 \%$ \\
Austenitic steels & - & $17 \%$ & $15 \%$ \\
Nickel superalloys & - & - & $5 \%$ \\
\hline
\end{tabular}

\section{TBCs structure and its application}

The desire for higher and higher performance has prompted research into solutions that will protect surfaces exposed to high temperatures from oxidation. By using a functional arrangement of two or more layers with different thermo-physical properties, and effective method of material surface protection has been obtained. With simultaneous cooling from the other side, the lifetime of the material has been increased.

\subsection{TBCs structure}

The low values of the thermal conductivity, low density, small modulus of elasticity facilitate reduction of thermal stresses and finally, high erosion resistance of TBCs [5] have determined that TBCs are successfully used in various branches of industry. Metal oxides such as $\mathrm{BeO}$, $\mathrm{CaO}, \mathrm{MgO}, \mathrm{Al}_{2} \mathrm{O}_{3}, \mathrm{Y}_{2} \mathrm{O}_{3}$, and $\mathrm{ZrO}_{2}$ are known for their low thermal conductivity. Thus they can act as a thermal barrier. Nevertheless, the high adhesion to the protected material, resistance to sharp temperature changes as well as oxidation resistance are additionally required from TBCs. Progress in materials engineering has made it possible to develop double-layer thermal insulation that fulfils these requirements. The most common is the twolayer system, which consists of a ceramic coating, TC (Top Coat), which prevents oxidation, and a layer BC (Bond Coat) with a metallic matrix, that improves adhesion to the surface to be coated. Furthermore, it is designed to reduce the stresses associated with different thermal expansion coefficient values [6]. The outer layer is made of $\mathrm{ZrO}_{2}$ stabilised by $\mathrm{Y}_{2} \mathrm{O}_{3}$ (YSZ). The thickness varies from $100 \mu \mathrm{m}$ (aircraft turbine blades) up to $2 \mathrm{~mm}$ (Diesel reciprocating engine) depending on the intended application [7]. As base layers, NiCRAlY, NiAl or $\mathrm{NiCr}$ are usually used. Their thicknesses are in the range of 50 to $500 \mu \mathrm{m}$. The thermophysical properties of the 8YSZ, $\mathrm{NiCoCrAlY}$ can be found in the literature $[5,7,8]$. Fig. 1 shows the thermophysical properties of a double-pipe system coated with TBCs.

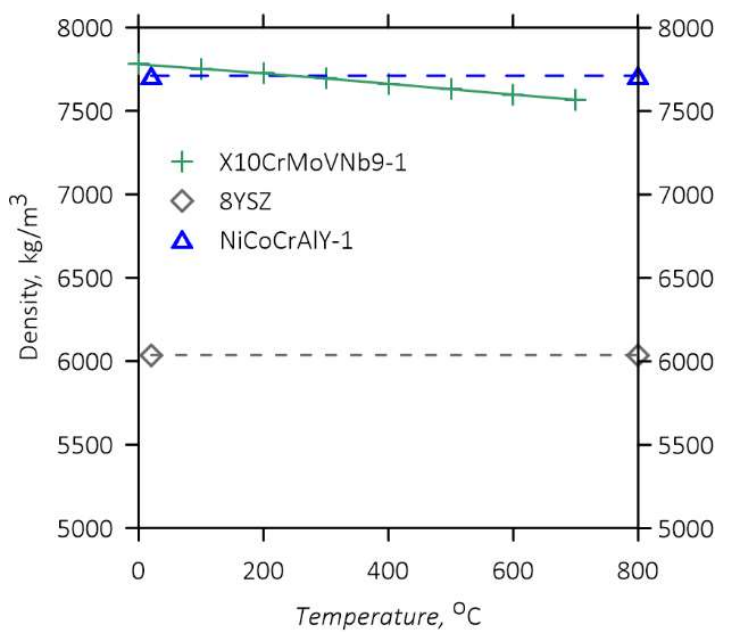

(a)

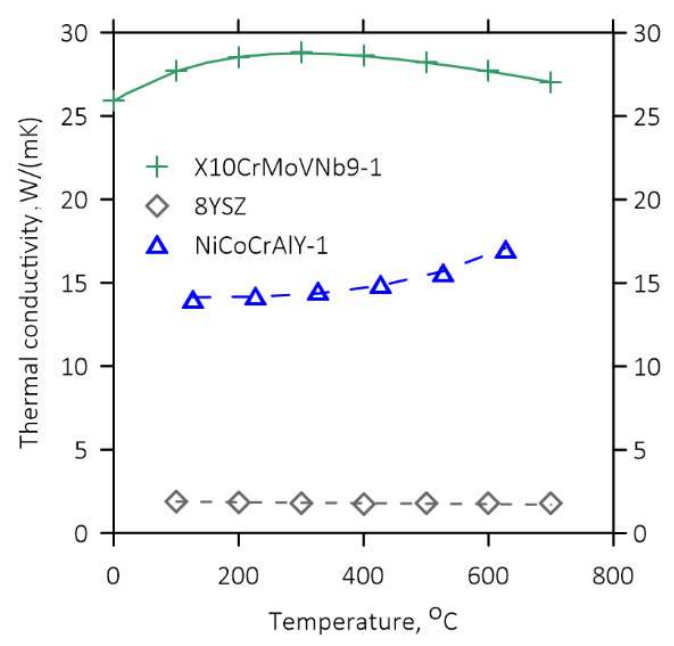

(b) 


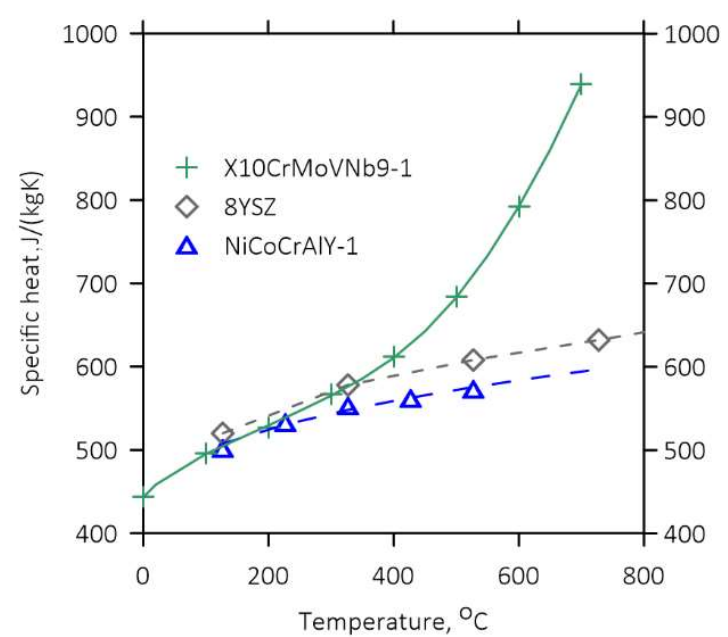

(c)

Fig. 1. Thermo-psychical properties of X10CrMoVNb9-1 (P91), 8YSZ, NiCoCrAlY: (a) Density; (b) Thermal conductivity; (c) Specific heat.

\subsection{TBCs application}

TBCs are considered as the essential protection for hightemperature exposed metals. With sufficient cooling of the material, its operating temperature can be decreased up to $100-300^{\circ} \mathrm{C}$ [9]. The use of TBCs has increased the efficiency of aircraft turbine engines. The turbine inlet temperature was raised above the melting point of the high-alloy steels used. Along with increased efficiency, reduced emission of pollutants and an extended lifetime of the turbine blades became expected. Due to TBCs, the lifetime of civil aviation jet engines has increased up to $30000 \mathrm{~h}$ [9]. The paper [10] shows that the use of TBCs resulted not only in a considerable reduction of nitrogen oxides, carbon monoxide and particulates in the exhaust of a reciprocating diesel engine but most importantly in a $5 \%$ reduction in fuel consumption and an increase in the lifetime of engine equipment. It is becoming increasingly common to use TBCs in the power generation industry. In [11], the desired structure of TBCs in the case of the steam turbine blade is investigated. The author highlights the possibility of changing the performance characteristics of steam turbines when using TBCs. The authors of the paper [12] point out the option of using TBCs to cool the primary steam pipeline, with secondary steam. In this case, the inner wall of the inner pipe is covered with a protective layer.

\section{Numerical modelling}

Significant progress in computer technology has made it possible to use numerical methods to solve complex physical problems. Computer modelling not only simplifies the design and optimisation process but also reduces its cost. When the issue involves components with large and complex geometry or transient operating states, numerical modelling shows its advantage over other methods. The work [13] highlights the use of CFD (Computational Fluid Dynamics) in the modelling process of transient operation of the superheater and its influence on material selection. The authors of [14] use computer modelling in the selection of appropriate TBCs coating thickness for different temperature ranges during turbine blade operation. The paper [12] analyses a design that uses TBCs to cool a steam pipeline in advanced ultrasupercritical power plants. The authors calculated the thermal stresses occurring in the pipe wall using a commercial heat transfer code. The results of this modelling were compared with the analytical approach that is used in the paper [15]. In [15], the thermal conductivity of the TBCs system is investigated. In the mentioned works, commercial codes were used to calculate the heat transfer processes. The work [13] highlights the main weakness of commercial software, which is the availability of computational power, especially when analysing transient states. Additionally, the heat transfer modelling at the liquid-solid boundary concerns the difficulty in the discretisation of a near-thewall layer. It is also required to use turbulence modelling. Thus, more and more often appropriate mathematical modelling is developed to enable the analysis of the full range of device operation in the area of the considered physical problems. Such an approach is used in works [16-18]. In these works, the evaluation of the nonstationary temperature field in the various operating states of power equipment was carried out. The Galerkin method [19] was applied in the above deliberations, which made it possible to develop advanced mathematical models. This paper presents an advanced mathematical model of a double-pipe system using TBCs to cool an ultra-supercritical steam pipeline (Fig. 2). This model is a distributed parameter model. It applies variable, as a function of temperature, material properties (Fig. 1). It adopts real steam parameters (IAPWS-IF97). It makes it possible to change the input parameters and therefore to perform a full analysis of the pipeline in transient states of the boiler operation. Another advantage of this model is the use of any correlation that determines the heat transfer coefficient, which is also dependent on the input parameters. The Nusselt number correlations are often compared with experimental studies, which shows their advantage over computational fluid dynamics. The steam pipeline is a thick-walled element. Since the mathematical model is a distributed parameter model, it is possible to study the non-stationary temperature field in both radial and axial directions. A comprehensive literature review concluded that the design concept presented in [12] does not have unsteady-state investigations. There are also no mathematical models that concern this design concept. The studies in the literature on transients of axisymmetric pipelines usually simplify the analysis to a onedimensional case, which shows the advantages of the developed model. In addition, the model allows for a shorter computation time. With this model, issues related to material strength and heat transfer can be considered. The simulation of boiler characteristics will allow us to fully understand the effect of TBCs coatings on the reduction of thermal stresses and the increase of the fatigue strength of thick-walled boiler components. 


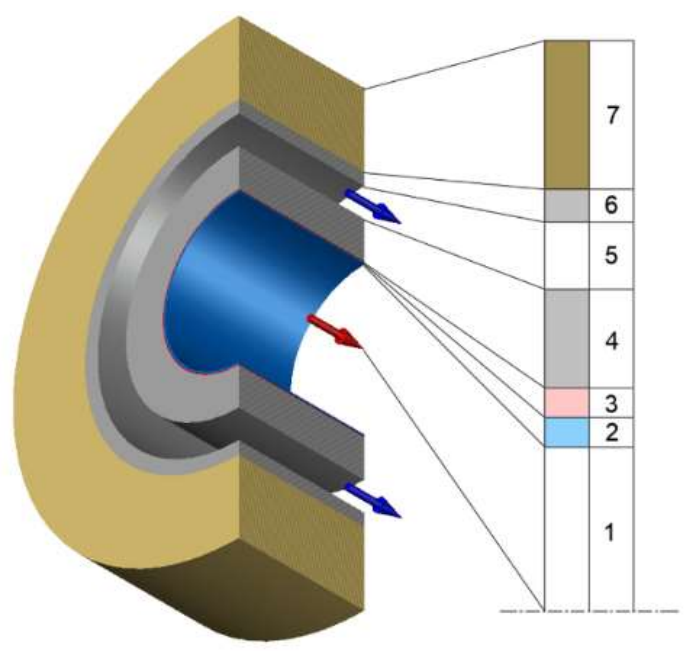

Fig. 2. The scheme of TBCs application for the cooling of ultra-supercritical steam pipeline: 1- ultra-supercritical steam, 2- top coat (TC), 3- bond coat (BC), 4- internal tube (T2), 5subcritical steam, 6- external tube (T2), 7- insulation.

Furthermore, it will enable the selection of appropriate coating parameters. Further testing of thick-walled boiler components with TBCs coatings will enable the development of procedures by which boiler start-up or shut-down time can be reduced. This is important at a time when the power grid system is more and more dependent on renewable energy sources.

\subsection{A mathematical model of the double-pipe system with TBCs application}

The scheme depicted in Fig. 2 may be presented in discrete form as in Fig. 3. The structure of the mathematical model is based on the differential heat conduction equation Eq. (2), by which it is possible to determine the temperature of any node.

$$
\rho(T) c(T) \frac{\partial T}{\partial t}=\frac{1}{r} \frac{\partial}{\partial r}\left(r k \frac{\partial T}{\partial r}\right)+\frac{\partial}{\partial x}\left(k \frac{\partial T}{\partial x}\right)
$$

For the i,j node representing the solid domain (Fig. 4), the corresponding heat balance (Eq. 3) can be written. The heat balance of the $\mathbf{i}, \mathbf{j}$ node (Eq. 4), which is located on the surface of the element (Fig. 5), is similar. Nevertheless, Newton's law of cooling must be applied. If we consider fluid as continuous if steam mass flow rate does not change along the channel, and finally if there is no friction, we can define the conservation of energy equation for the $\mathbf{i}, \mathbf{j}$ node of the steam finite volume element, Fig 6., Eq. (5). Newton's cooling law should also be used in this case. Eqs (3-5) can be combined into a set of differential equations with time derivatives and solved using the Runge-Kutta method. The heat transfer coefficient, that appears in eqs (4) and (5) is derived from the correlation (6) and (7) proposed by Taler [27]. Eq. (6) refers to the undeveloped flow, Eq. (7) is valid for the finite channel length and developed velocity profile. Range its application: $0.1 \leq \operatorname{Pr} \leq 1000,2300 \leq \operatorname{Re} \leq 10^{6}$.

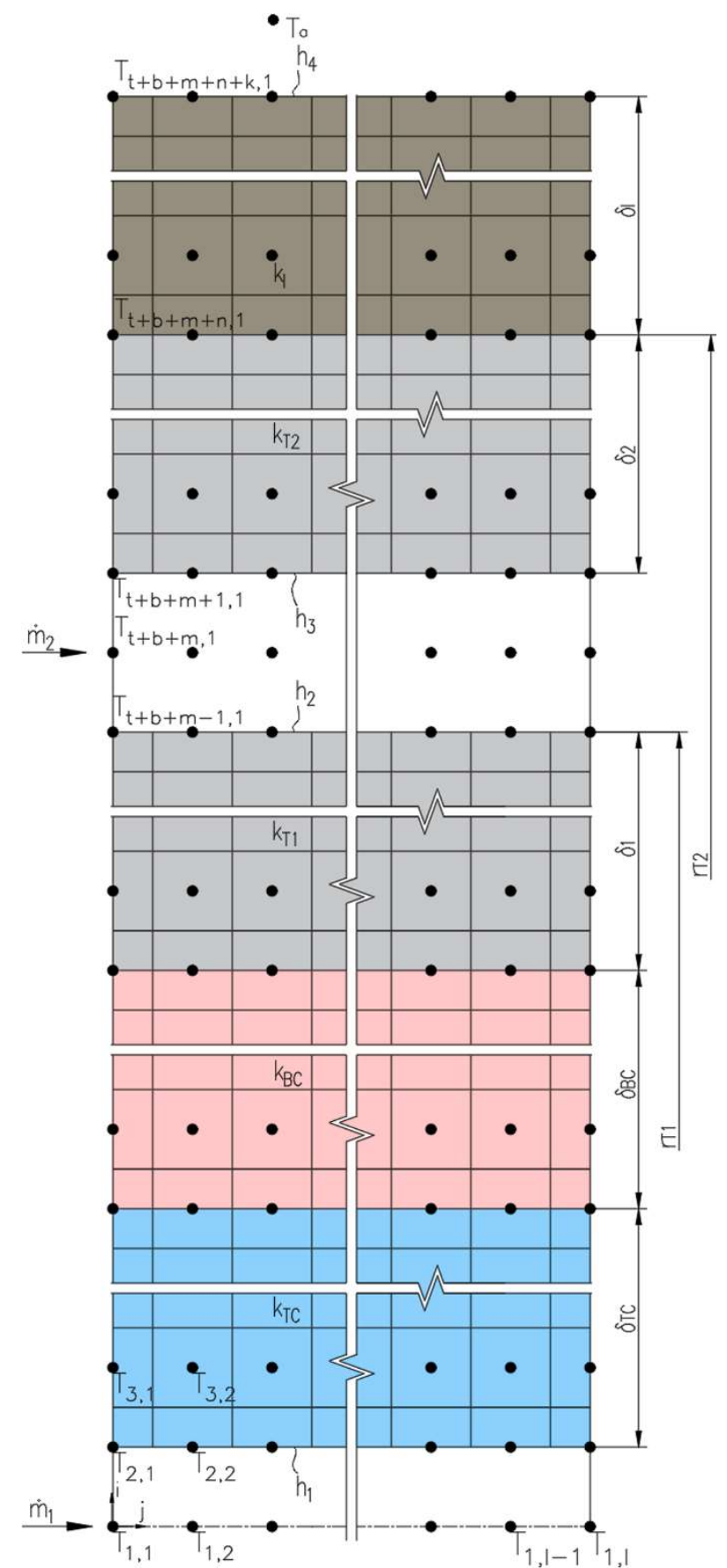

Fig. 3. Discrete model.

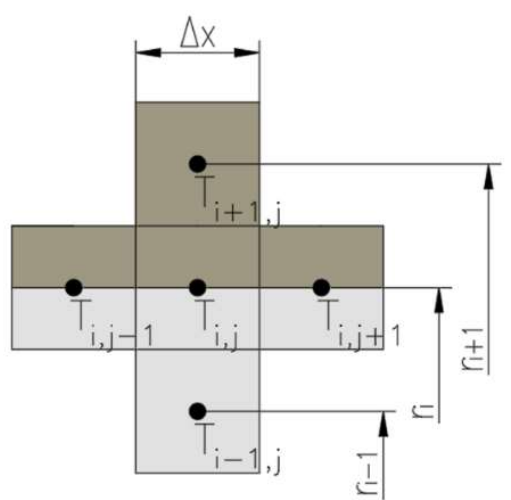

Fig. 4. Solid element node location. 


$$
\begin{gathered}
\frac{d T_{i, j}}{d t} \Delta x\left[\left(\left(\frac{r_{i}+r_{i+1}}{2}\right)^{2}-r_{i}^{2}\right) \rho_{i}\left(T_{i, j}\right) c_{i}\left(T_{i, j}\right)\right. \\
\left.+\left(r_{i}^{2}-\left(\frac{r_{i}+r_{i-1}}{2}\right)^{2}\right) \rho_{i-1}\left(T_{i, j}\right) c_{i-1}\left(T_{i, j}\right)\right]= \\
\left.\Delta x\left(\frac{r_{i-1}+r_{i}}{r_{i}-r_{i-1}}\right) k_{i-1}\right|_{T_{i, j}} ^{T_{i-1, j}}\left(T_{i-1, j}-T_{i, j}\right)+ \\
\left.\Delta x\left(\frac{r_{i}+r_{i+1}}{r_{i+1}-r_{i}}\right) k_{i}\right|_{T_{i, j}} ^{T_{i+1, j}}\left(T_{i+1, j}-T_{i, j}\right)+ \\
\left.\frac{1}{\Delta x}\left(r_{i}^{2}-\left(\frac{r_{i-1}+r_{i}}{2}\right)^{2}\right) k_{i-1}\right|_{T_{i, j}} ^{T_{i, j-1}}\left(T_{i, j-1}-T_{i, j}\right)+ \\
\left.\frac{1}{\Delta x}\left(r_{i}^{2}-\left(\frac{r_{i-1}+r_{i}}{2}\right)^{2}\right) k_{i-1}\right|_{T_{i, j}} T_{i, j+1}\left(T_{i, j+1}-T_{i, j}\right)+ \\
\left.\frac{1}{\Delta x}\left(\left(\frac{r_{i}+r_{i+1}}{2}\right)^{2}-r_{i, j}^{2}\right) k_{i}\right|_{T_{i, j}} ^{T_{i, j-1}}\left(T_{i, j-1}-T_{i, j}\right)+ \\
\left.\frac{1}{\Delta x}\left(\left(\frac{r_{i}+r_{i+1}}{2}\right)^{2}-r_{i}^{2}\right) k_{i}\right|_{T_{i, j}} ^{T_{i, j+1}}\left(T_{i, j+1}-T_{i, j}\right)
\end{gathered}
$$

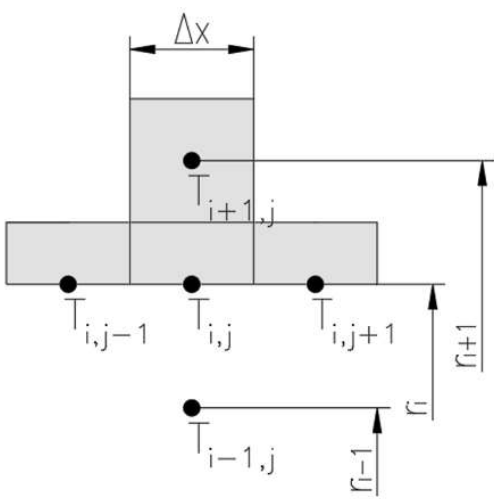

Fig. 5. Solid-fluid element node location.

$$
\begin{gathered}
\frac{d T_{i, j}}{d t} \Delta x\left(\left(\frac{r_{i}+r_{i+1}}{2}\right)^{2}-r_{i}^{2}\right) \rho_{i}\left(T_{i, j}\right) c_{i}\left(T_{i, j}\right)= \\
\left.\Delta x\left(\frac{r_{i}+r_{i+1}}{r_{i+1}-r_{i}}\right) k_{i}\right|_{T_{i, j}} ^{T_{i+1, j}}\left(T_{i+1, j}-T_{i, j}\right)+ \\
\left.\frac{1}{\Delta x}\left(\left(\frac{r_{i}+r_{i+1}}{2}\right)^{2}-r_{i}^{2}\right) k_{i}\right|_{T_{i, j}} ^{T_{i, j-1}}\left(T_{i, j-1}-T_{i, j}\right)+ \\
\left.\frac{1}{\Delta x}\left(\left(\frac{r_{i}+r_{i+1}}{2}\right)^{2}-r_{i}^{2}\right) k_{i}\right|_{T_{i, j}} ^{T_{i, j+1}}\left(T_{i, j+1}-T_{i, j}\right)+ \\
2 r_{i} \Delta x h_{i-1}\left(T_{i-1, j}-T_{i, j}\right)
\end{gathered}
$$

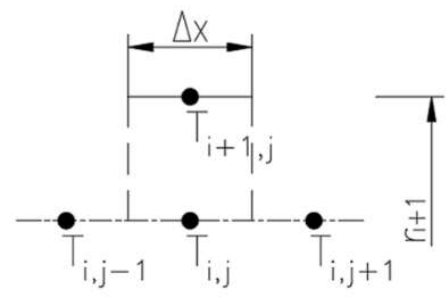

Fig. 6. Steam element.

$$
\begin{aligned}
& \pi \Delta x r_{i}^{2} \rho_{i}\left(T_{i, j}\right) c_{p}\left(T_{i, j}\right) \frac{d T_{i, j}}{d t} \\
& =\left.\dot{m}_{h} c_{p}\right|_{T_{i, j}} ^{T_{i, j-1}} \frac{1}{2}\left(T_{i, j-1}+T_{i, j}\right) \\
& -\left.\dot{m}_{h} c_{p}\right|_{T_{i, j+1}} ^{T_{i, j}} \frac{1}{2}\left(T_{i, j+1}+T_{i, j}\right) \\
& +2 \pi r_{i} \Delta x h_{i-1}\left(T_{i+1, j}-T_{i, j}\right) \\
& N u_{1}=\left[83.09+0.6^{3}\right. \\
& +\left(1.953\left(\operatorname{RePr} \frac{d_{i n}}{L}\right)^{\frac{1}{3}}-0.6\right)^{3} \\
& \left.+0.924 \stackrel{\frac{1}{3}}{\operatorname{Pr}}\left(\operatorname{Re} \frac{d_{\text {in }}}{L}\right)^{\frac{1}{2}}\right]^{\frac{1}{3}} \\
& N u_{2}=N u_{1}+\frac{\frac{\xi}{8}(R e-2300) P r^{1.008}}{1.08+12.39 \sqrt{\frac{\xi}{8}}\left(\operatorname{Pr}^{\frac{2}{3}}-1\right)} \\
& \left(1+\left(\frac{d_{i n}}{L}\right)^{2 / 3}\right)\left(\frac{P r}{P r_{w}}\right)^{0.11} \\
& R e=\frac{\rho w D}{\mu} ; \operatorname{Pr}=\frac{c_{p} \mu}{k} ; N u=\frac{h D}{k}
\end{aligned}
$$

\subsection{The CFD model}

The geometry and operating parameters of the system shown in Table 2 were used to develop both models. In the case of the mathematical model, the algorithm allows all parameters to be changed. The corresponding CFD model was constructed according to [13]. Three discrete models were created and the effect of surface element size on the results was investigated (Fig. 7). In addition, in order a correct determination of the velocity and temperature profile, the near-the-wall layer was prepared so that $y+=1$. The parameters of the discrete models are shown in Table 3. Mesh 3 has been selected. Fig. 8 shows a comparison between the two models for the temperature distribution on the inner pipe wall at the end of the pipe. As can be observed, the results of both modelling converge.

Table 1. Geometry and working parameters of double-pipe system with a protective layer.

\begin{tabular}{lcccc}
\hline Layer & $\mathrm{t},{ }^{\circ} \mathrm{C}$ & $\mathrm{p}, \mathrm{MPa}$ & $\emptyset, \mathrm{mm}$ & $\mathrm{a}, \mathrm{mm}$ \\
\hline Steam & 590 & 26.5 & & \\
Top coat & & & 317.9 & 2.5 \\
Bond coat & & & 322.9 & 0.5 \\
Tube 1 & & & 323.9 & 50 \\
Steam & 450 & 5.8 & & \\
Tube 2 & & & 457 & 10 \\
Insulation & & & 857 & 200 \\
\hline
\end{tabular}


Table 1. The CFD discretization parameters.

\begin{tabular}{llll}
\hline Mesh no. & \multicolumn{1}{c}{$\mathbf{1}$} & \multicolumn{1}{c}{$\mathbf{2}$} & \multicolumn{1}{c}{$\mathbf{3}$} \\
\hline $\begin{array}{l}\text { Element size in axial } \\
\text { direction }\end{array}$ & $0.02 \mathrm{~m}$ & $0.015 \mathrm{~m}$ & $0.012 \mathrm{~m}$ \\
$\begin{array}{l}\text { No. of elements: } \\
\text { Circumference }\end{array}$ & 80 & 100 & 120 \\
Tube 1 wall & 4 & 7 & 9 \\
Tube 2 wall & 2 & 3 & 4 \\
Supercritical steam & & & \\
$\begin{array}{l}\text { First layer height } \\
\text { Layers }\end{array}$ & $\mathrm{y}^{+}=1$ & $\mathrm{y}^{+}=1$ & $\mathrm{y}^{+}=1$ \\
Sub-critical steam & 52 & 52 & 52 \\
$\begin{array}{l}\text { First layer height } \\
\text { Layers }\end{array}$ & $\mathrm{y}^{+}=1$ & $\mathrm{y}^{+}=1$ & $\mathrm{y}^{+}=1$ \\
Nodes & 40 & 40 & 40 \\
\hline
\end{tabular}

\section{Results}

A double-pipe system with a length of $10 \mathrm{~m}$ was the object of the research. Due to the high steam parameters associated with the high boiler output and consequently the high velocity of both fluids, the change in steam temperature at the outlet of the system is negligible. Thus, attention has been paid to the temperature distribution on the wall of the inner pipe. Fig. 8 shows the influence of the use of thermal barrier coatings on the temperature distribution in the wall of the internal pipe (tube no. 1). The results of mathematical modelling were compared with the results of CFD modelling. The temperature distribution in both cases is almost the same. The mathematical model has a huge advantage when it comes to computation time. Analysis of any, even full transient operating state of such a pipeline can be carried out in a very short time. In the case of CFD modelling, with limited computing power, simulation of transients is almost impossible. Figs. 9-10 present the stationary temperature field at the wall of the internal tube. As it can be observed, the temperature difference between the inner and outer surfaces is the same. However, when using TBCs, the sharp temperature drop occurs in the protective layer, while the pipe wall temperature gradient is no longer so high. The transient analysis studied the temperature change of the inner and outer surface of the internal tube as a result of step temperature change (Fig. 11) of the ultra-supercritical steam. The results were compared with the case in which the thick-walled component is covered with TBCs (Fig. 12). Furthermore, Fig. 13 shows how the temperature distribution at the pipe wall changes at the moment when the temperature of the steam is increased by the same step (from 590 to $600{ }^{\circ} \mathrm{C}$ ), i.e. for the moment $\mathrm{t}=0 \mathrm{~s}$ and for the moment $\mathrm{t}=5 \mathrm{~s}$. The non-stationary temperature field analysis shows that even a small step increase in the temperature of the hot steam can cause an increase in the temperature difference between the inner and outer walls. A higher temperature gradient can cause the permissible thermal stresses to be exceeded. The use of a protective layer should minimise this effect, as can be observed in Figs. 12, 14. Since the largest temperature drop occurs at the coating, the temperature change in the pipe at transients will be very small. In the boilers, the start-up and shut-down rates are defined by standards. Normally, due to the increase in temperature difference between the inner and outer wall, the heating rates of thick-walled components such as the drum are limited to $5-10 \mathrm{~K} / \mathrm{min}$. The use of TBCs significantly reduces the effect of a change in ambient temperature on the temperature difference within the wall of the component. Moreover, this difference is smaller, which not only makes it possible to improve the dynamics of their operation but also to use more cost-effective materials. This may encourage further research into the coating itself and into changing the heating or cooling rate of thick-walled components. Nevertheless, it would be desirable to make a simulation of the full transient operating state of the boiler: from start-up to shut-down. The results presented show the correct behaviour of the mathematical model.

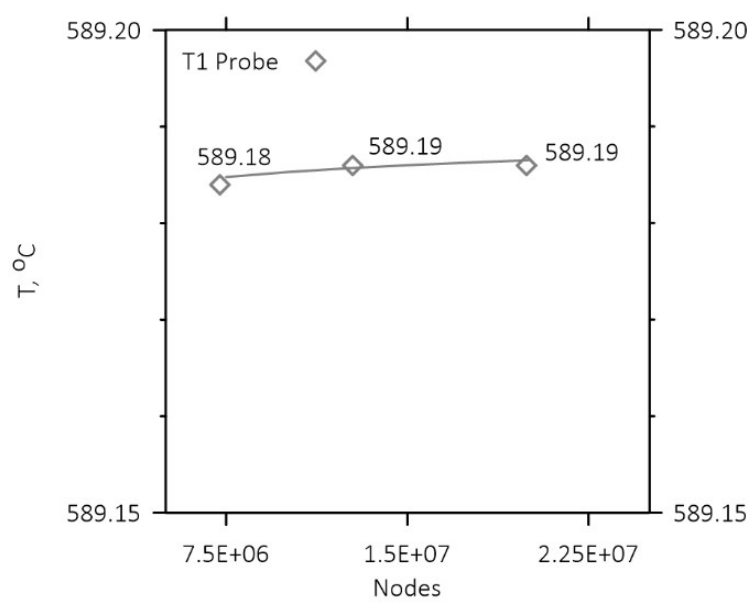

Fig. 7. Convergence of the results in the case of the random temperature probe.

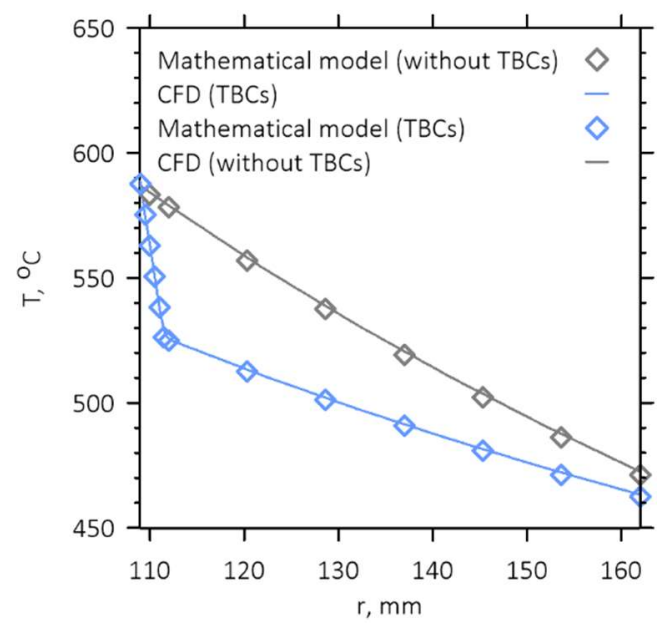

Fig. 8. CFD and mathematical model summary of temperature distribution on the internal pipe wall. 


\begin{tabular}{|l} 
Temperature \\
\hline 588.8 \\
576.2 \\
563.7 \\
551.2 \\
538.7 \\
526.2 \\
513.7 \\
501.2 \\
488.7 \\
476.1 \\
463.6
\end{tabular}

Fig. 9. CFD and mathematical model summary of temperature distribution on the internal pipe wall.

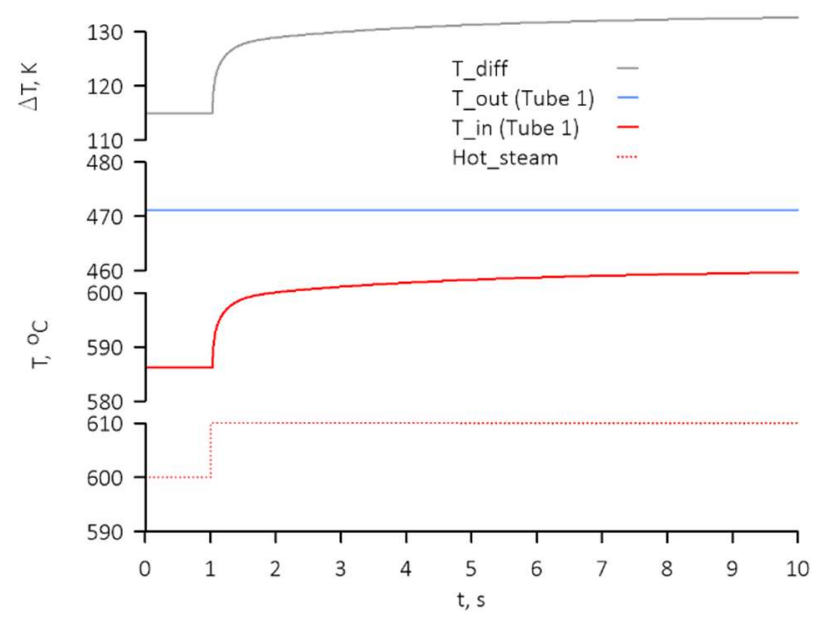

Fig. 11. Temperature change at the inner wall and on the outer wall of the pipe as a function of the step change in steam temperature.

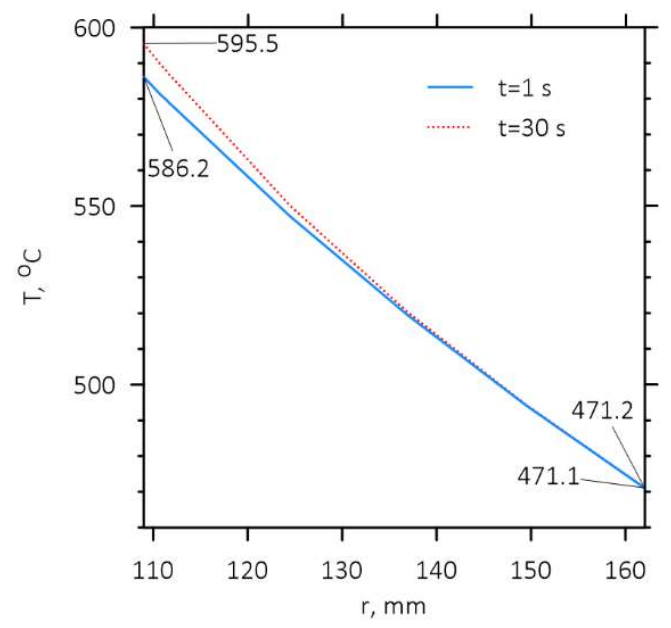

Fig. 13. Temperature distribution of the inner wall and on the outer wall of the pipe as a function of the step change in steam temperature.

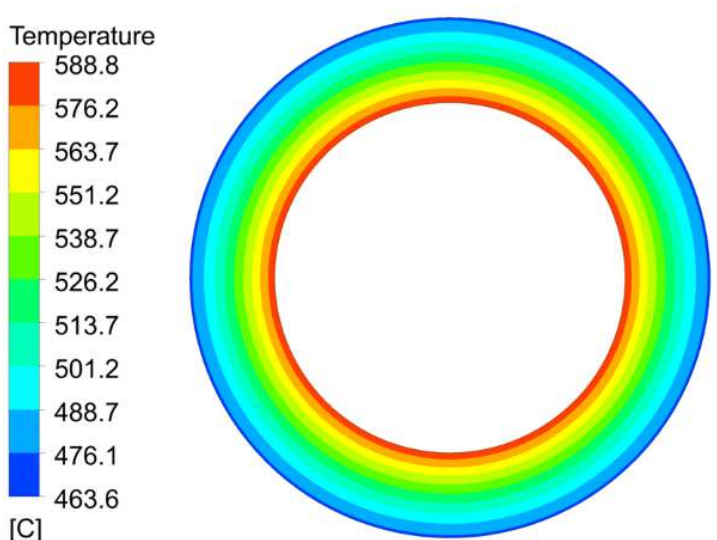

Fig. 10. CFD and mathematical model summary of temperature distribution on the internal pipe wall.

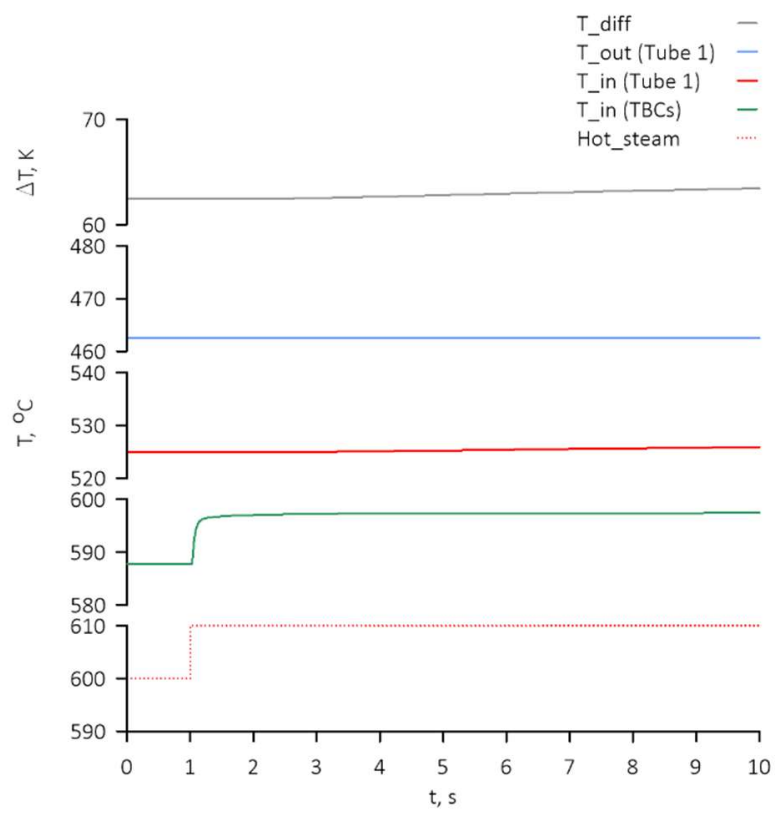

Fig. 12. Temperature change at the inner wall, behind the protective layer and on the outer wall of the pipe as a function of the step change in steam temperature.

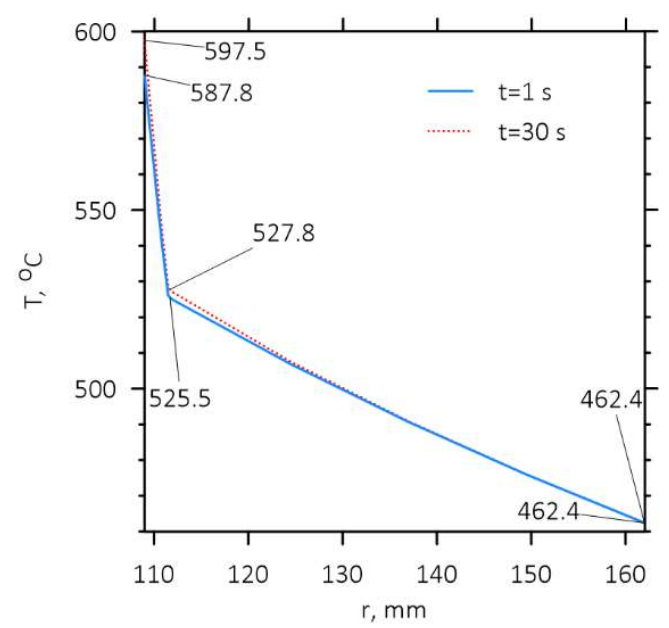

Fig. 14. Temperature distribution of the inner wall and on the outer wall of the pipe as a function of the step change in steam temperature. 


\section{Conclusions}

TBCs coatings can reduce the wear and tear on expensive alloys that are used in the design of ultra-supercritical boilers. The space and aerospace industries have been using TBCs successfully for several decades. However, there is a lack of research that focuses on their use in highpressure steam boiler components. Their properties can increase the creep and fatigue resistance of thick-walled boiler components. In the era of increasing demand for electricity and a greater share of renewable energy sources, the power availability and efficiency of newbuild units is one of the most important criteria in the design process. Consequently, there is a need to investigate coatings and their effects on stressed boiler components. It is also necessary to study their performance characteristics, which is limited by thermal stresses resulting from the temperature difference between the inner and outer wall. In transient operating states, this difference can easily exceed the permissible value. This work aimed to propose a mathematical model of a high-efficiency pipeline cooling system in which ultra-supercritical steam flows. The system consists of two pipes. The surface of the inner pipe, in which ultrasupercritical steam flows, is coated with TBCs. Steam with lower parameters flows through the outer channel so that the wall of the inner pipe can be cooled. In the proposed model, the Galerkin method is used so that the time-varying temperatures at each node of the finite element can be determined. The direct results show the correct behaviour of the mathematical model, which was also compared with the corresponding CFD model. The use of a protective coating with a low thermal conductivity coefficient results in a reduction of the temperature gradient in the pipe wall. Further work will focus on comparing the results of the numerical calculations with the analytical calculations and measurements from the test stand. The validation of the work will allow for a complete analysis of the transient state of the pipeline operation. The proposed model can also be the subject of studies concerning fracture of this type of coatings, as well as studies that will focus on improving the start-up or shut-down process of the units.

\section{References}

1. S.C. Stultz, J.B. Kitto, Steam its generation and use. 41st edition, The Babcook \& Wilcox Company, USA (2005)

2. D. Zhang, Ultra-supercritical coal power plants Materials, technologies and optimisation, Woodhead Publishing Series in Energy: Number 41, UK (2013)

3. A. Gianfrancesco, Materials for Ultra-supercritical and Advanced Ultra-supercritical Power Plants, Woodhead Publishing Series in Energy, 104 (2017)

4. A. Hernas, Materiały do budowy kotłów na parametry nadkrytyczne, Nowa Energia, 5-6 (2013)
5. K.S. Ravlchandran, K. An, R.E. Dutton and S.L. Semlatin, Microstructure and thermal conductivity of layered Thermal Barrier Coatings processed by plasma spray and physical vapor deposition techniques, MRS Proceedings, 434, no. 27, Cambridge University Press (2011)

6. P. Sosnowy, M. Góral, S. Dudek, M. Drajewicz and T. Gancarczyk, Mikrostruktura powłokowych barier cieplnych natryskiwanych metodą APS z zastosowaniem nowych proszków ceramicznych, Przegląd spawalnictwa, 8, no. 84 (2012)

7. K.W. Schlichting, N.P. Padture, P.G. Klemens, Thermal conductivity of dense and porous yttriastabilized zirconia, Journal of Materials Science, $\mathbf{3 6}$ (2001)

8. M. Radovic, E. Lara-Curzio, R. Trejo, H. Wang and W.D. Porter, Thermo-Physical Properties of Ni-YSZ as a Function of Temperature and Porosity, Ceramic Engineering and Science Proceedings, 27, no. 4 (2008)

9. N.P. Padture, M. Gell and E.H. Jordan, Thermal barrier Coatings for Gas-Turbine Engine Applications, Science, 296, no. 5566 (2002)

10. D.W. Parker, Thermal barrier coatings for gas turbines, automotive engines and diesel equipment, Materials \& Design, 13, no. 6 (1992)

11. T. Huttel, Investigation of the High Temperature Performance of Thermal Barrier Coating Systems for Steam Turbine Applications, Ph.D. dissertation, RWTH Aachen University, Germany (2010)

12. X. Guo et al., Thermal and stress analyses of a novel coated steam dual pipe system for use in advanced ultra-supercritical power plant, Pressure Vessels and Piping, 176, 103903 (2019)

13. M. Granda, M. Trojan, D. Taler, CFD analysis of steam superheater operation in steady and transient state, Energy, 199, 117423 (2020)

14. B. Li, X. Fan, D. Li and P. Jiang, Design of Thermal Barrier Coatings Thickness for Gas Turbine Blade Based on Finite Element Analysis, Mathematical Problems in Engineering (2017)

15. K.J. An, Assessment of the Thermal Conductivity of Yttria-Stabilized Zirconia Coating, Materials Transactions, 55, no. 1, (2014)

16. Kaczmarski K., Numerical model of steam pipeline with thermal insulation, International Journal of Numerical Methods for Heat \& Fluid Flow, 30 (5), (2019)

17. Taler D., Kaczmarski K., Mathematical Modelling of the Transient Response of Pipeline, Journal of Thermal Science, 25 (6), (2016)

18. M. Trojan, M. Granda, Modeling of the boiler economizer, Matec Web of Conferences, 240, 050034 (2018)

19. J. Taler, P. Duda, Solving Direct and Inverse Heat Conduction Problems, Springer, 2006

20. D. Taler, Numerical Modelling and Experimental Testing of Heat Exchangers, 1st ed., Springer (2019) 